\title{
Unemployment, birthweight, and growth in the first year
}

\author{
T J COLE, M L DONNET, AND J P STANFIELD
}

Dunn Nutrition Unit, Cambridge, and Social Paediatric and Obstetric Research Unit, Glasgow

SUMMARY In a cross sectional sample of 655 Glasgow babies the mean birthweight, after adjusting for other factors, of those with unemployed fathers was $150 \mathrm{~g}$ less $(\mathrm{P}<0.02)$ than for babies whose fathers were employed. A longitudinal study of 107 babies from 2 contrasting areas in Glasgow one of which was a socially deprived area was carried out concurrently. The deficit in length of $2.6 \%$ for infants from the deprived area at age 12 months was completely explained by adjusting for length at 1 month, father's height, and father's employment status $(P<0.01)$. The effect of unemployment on the babies' birthweight was not affected by adjustment for sccial class. Unemployment may be related to poor infant growth in inner city areas and a national study is needed to see if the recent rise in unemployment has affected this association.

Children of high social class weigh more at birth and have better subsequent growth than lower social class children. ${ }^{12}$ Three factors in particular have been implicated in the poorer growth and development of lower social class children-family composition (either single parent or many children), low income, and poor housing. ${ }^{1}$ Families suffering multiple deprivation are concentrated in disadvantaged areas of industrial cities, in Scotland more than in England, ${ }^{\mathbf{1}}$ and within Scotland, particularly on Clydeside. ${ }^{3-5}$

In Glasgow the major city on Clydeside there is a high prevalence of short stature. ${ }^{6}$ To clarify the link between urban deprivation and growth deficit, we carried out a longitudinal study into the growth of infants from 2 contrasting areas of Glasgow ${ }^{7}-$ Blackhill, a deprived area with a high rate of unemployment, and Carntyne which is more representative of the city as a whole. A cross sectional survey of Glasgow infants was carried out concurrently to provide background data for the city. The surveys were carried out during 1975 and 1976.

\section{Material and methods}

Subjects. The 2 longitudinal samples consisted of consecutive births notified to the local health visitor. Babies were first seen at the clinic aged between 4 and 6 weeks and, where possible, every 4 weeks thereafter. Of the initial 78 babies in Blackhill and 64 in Carntyne, 24 and 11 respectively dropped out by age 12 months ( 15 and 8 respectively had moved away). Taken together, the non-responders were very similar to the responders in most respects, notably social class, employment status, birthweight, and length at 1 month. For both birthweight and length at 1 month, however, the non-responders in Blackhill and Carntyne were similar to each other and were mid-way between the responders in the 2 places.

The cross sectional sample was drawn randomly and stratified for social class from all babies born and still living in the city of Glasgow. The babies were allocated to 1 of 5 age groups - 6 weeks, 3, 6, 9 or 12 months-and were seen within 3 days of the nominal age. A total of 655 babies were seen, 37 others could not be contacted, and the parents of 20 refused. Table 1 gives the social class distribution of the babies in the 3 samples. Social class was recorded as unknown where there was no man in the household, or where the man's job was unclassifiable (if, for example, he was in the Armed Services).

Table 1 Distribution by social class of Glasgow infants $(\%)$

\begin{tabular}{lccc}
\hline Social class & $\begin{array}{l}\text { Cross sectional } \\
\text { sample } \\
(n=655)\end{array}$ & $\begin{array}{l}\text { Blackhill } \\
\text { sample } \\
(n=78)\end{array}$ & $\begin{array}{l}\text { Carntyne } \\
\text { sample } \\
(n=64)\end{array}$ \\
\hline 1 & $6 \cdot 1$ & $0 \cdot 0$ & $1 \cdot 6$ \\
2 & $9 \cdot 5$ & $1 \cdot 3$ & $6 \cdot 2$ \\
3 & $48 \cdot 1$ & 12.8 & $68 \cdot 8$ \\
4 & $15 \cdot 7$ & $2 \cdot 6$ & $6 \cdot 2$ \\
5 & 19.2 & 71.8 & 9.4 \\
Not known & 1.4 & $11 \cdot 5$ & $7 \cdot 8$ \\
\hline
\end{tabular}


Table 2 Social factors and birthweight by social class and sample in Glasgow infants

\begin{tabular}{|c|c|c|c|c|c|c|c|c|}
\hline & \multicolumn{5}{|c|}{ Social class } & \multicolumn{3}{|c|}{ Sample } \\
\hline & 1 & 2 & 3 & 4 & 5 & $\mathbf{X}$ & B & $\mathbf{C}$ \\
\hline No of rooms in house & $4 \cdot 0$ & $3 \cdot 7$ & $3 \cdot 1$ & $3 \cdot 1$ & $3 \cdot 1$ & $3 \cdot 2$ & $2 \cdot 8$ & $2 \cdot 9$ \\
\hline No of people in family & $3 \cdot 9$ & $4 \cdot 5$ & $4 \cdot 3$ & $4 \cdot 7$ & $5 \cdot 1$ & $4 \cdot 5$ & $5 \cdot 5$ & $4 \cdot 0$ \\
\hline No of children under 5 & $1 \cdot 4$ & $1 \cdot 5$ & $1 \cdot 5$ & $1 \cdot 6$ & $1 \cdot 6$ & $1 \cdot 5$ & $1 \cdot 8$ & $1 \cdot 3$ \\
\hline Outside lavatory $(\%)$ & 0.0 & 0.0 & 3.8 & $3 \cdot 9$ & $6 \cdot 4$ & $3 \cdot 7$ & 0.0 & $5 \cdot 2$ \\
\hline No hot water $(\%)$ & 0.0 & $3 \cdot 2$ & $5 \cdot 1$ & $6 \cdot 8$ & $9 \cdot 6$ & $5 \cdot 8$ & 9.4 & $3 \cdot 5$ \\
\hline Father unemployed $(\%)$ & 0.0 & 0.0 & $3 \cdot 8$ & $4 \cdot 9$ & $32 \cdot 5$ & $9 \cdot 0$ & $56 \cdot 5$ & $3 \cdot 4$ \\
\hline Mother's education score & $3 \cdot 9$ & $2 \cdot 4$ & $1 \cdot 3$ & $1 \cdot 1$ & $1 \cdot 0$ & $1 \cdot 5$ & $1 \cdot 0$ & $1 \cdot 2$ \\
\hline Mother's height (m) & 1.62 & $1 \cdot 60$ & 1.60 & $1 \cdot 59$ & $1 \cdot 58$ & 1.60 & $1 \cdot 57$ & $1 \cdot 61$ \\
\hline Father's height (m) & $1 \cdot 76$ & $1 \cdot 75$ & $1 \cdot 74$ & $1 \cdot 71$ & $1 \cdot 72$ & $1 \cdot 73$ & $1 \cdot 68$ & $1 \cdot 75$ \\
\hline Birthweight (g) & 3507 & 3294 & 3350 & 3244 & 3273 & 3322 & 3040 & 3337 \\
\hline
\end{tabular}

$\mathrm{X}=$ cross sectional sample $\mathbf{B}=$ Blackhill sample $; \mathrm{C}=$ Carntyne sample.

Data and methods. Data collected on each child included length, a 24 hour dietary recall, and details of recent illnesses. The information was collected monthly in Blackhill and Carntyne and once only in the cross sectional survey. In addition mothers completed a social factors questionnaire and birthweights and gestational ages were obtained from hospital records. Table 2 summarises the questions asked, shows the effect of social class on the replies, and the differences between Blackhill and Carntyne. Mean birthweights are also given, which unlike the social factors showed little trend with social class. About $5 \%$ of the data on birthweight, gestational age, and father's height were unknown while up to $2 \%$ of the other data were missing. Numbers in the subsequent analyses were thus somewhat reduced.

Longitudinal morbidity was summarised by 2 illnesses-diarrhoea/vomiting and respiratory disease, of 3 degrees of severity - while in the cross sectional study morbidity was expressed in terms of hospital admissions. The differences in 'months at risk' between age groups in the cross sectional study were taken into account by fitting a separate constant term for each age group as described below. The 24 hour dietary recalls were converted to nutrient intakes and expressed as percentages of the median Glasgow intake for age and sex. ${ }^{7}$ In the longitudinal study the nutrient percentages for each visit were averaged over the year. Smoking habits were recorded in the longitudinal study but not in the cross sectional study.

Statistical analysis. The analysis was designed to identify factors associated with growth either before or after birth. Growth postpartum is, however, strongly related to growth in utero, as reflected by birthweight. Length in the first year was therefore adjusted for birthweight (in the cross sectional study) or length at the first visit (longitudinal sample) to give an index of growth since birth. The birthweight adjustment in the cross sectional sample was done for each age group separately as the regression of length on birthweight was significantly less steep $(P<0.001)$ in the older age groups. This also necessitated fitting a separate constant term for each age group, so that differences in mean flength between age groups were adjusted for.

Relative length in the cross sectional sample was transformed to its natural logarithm and multiplied by 100 to give results in percentage units. Length ing the longitudinal sample was adjusted for sex and age by expressing it as a percentage of the appropriate reference value derived from the cross sectional sample. $^{8}$ These 2 definitions of percentage are effectively the same as can be seen by considering a child whose length is, for example, $93 \%$ of the reference value. When $93 \%$ is expressed relative to the mean (that is $100 \%$ ) it becomes $-7 \%$, whereas $100 \log (93 / 100)$ gives $-7 \cdot 3 \%$.

To find those factors which accounted best for the observed variation in growth, stepwise multiple regression was used. A group of factors all significant at the $5 \%$ level or better was found, while the remaining factors were all non-significant at the $10 \%$ level. The absence of outlying observations was confirmed using residual plots.

\section{Results}

Birthweight. The main factor affecting birthweight in the cross sectional study was gestational age. After adjusting for this 5 other factors significantly related to birthweight were identified (Table 3). The babies of primiparas were lighter than those of multiparas but among the latter there was no obvious trend between birthweight and parity. In addition to baby's sex and mother's height and parity, 2 social factors were significant-father's employment status $(P<0.02)$ and the number of rooms in the house 
Table 3 Factors affecting birthweight ( $g$ ) in 601 Glasgow infants from the cross sectional sample, after adjusting for gestational age. (Each factor adjusted for the remaining factors)

\begin{tabular}{lll}
\hline Factor & $\begin{array}{l}\text { Regression coefficient } \\
(\text { SEM })\end{array}$ & Significance \\
\hline Mother's height $(\mathrm{m})$ & $+1401(287)$ & $\mathbf{P}<0.001$ \\
Female sex & $-143(34)$ & $\mathbf{P}<0.001$ \\
Primipara & $-145(35)$ & $\mathbf{P}<0.001$ \\
Father unemployed & $-149(61)$ & $\mathbf{P}<0.02$ \\
No rooms in house & $+35(17)$ & $\mathrm{P}<0.05$ \\
\hline
\end{tabular}

$(P<0.05)$. Seven other social factors including father's height and social class were tried but were found to be irrelevant. There remained the possibility that the 2 significant social factors (father's employment status and number of rooms) represented, at least partially, differences between rather than within the social classes. This was checked by adjusting for social class as well, which although non-significant itself had the effect of making 'rooms in the house' non-significant $(P>0.05)$.

Repeating the analysis of Table 3 on 116 Blackhill and Carntyne babies identified sex, father's height, and mother's smoking as the main factors affecting birthweight (Table 4). Mother's smoking was associated with a deficit of nearly $200 \mathrm{~g}$ in birthweight. No social factors were important but unemployment was close to significance $(P<0 \cdot 1)$ with an effect of $-183 \mathrm{~g}$. Adjusting for the relevant factors reduced the birthweight deficit in Blackhill from $323 \mathrm{~g}(\mathrm{P}<0.01)$ to $139 \mathrm{~g}(\mathrm{P}>0 \cdot 1)$.

Babies' length in the first year. Length adjusted for birthweight in the cross sectional sample was highly significantly less in girls and greater for taller mothers and fathers (Table 5). Two social factors were also significantly related to length; outside lavatory (positively) and the number of children aged under 5 (negatively). Adjusting for social class had no appreciable effect and no dietary or morbidity factors were important.

In the pooled longitudinal sample (Table 6) length at 12 months adjusted for length at 1 month was highly significantly related to father's height $(P<0.001)$ and also to whether or not the father was

Table 4 Factors affecting birthweight $(g)$ in 116 infants from Blackhill and Carntyne after adjusting for gestational age. (Each factor adjusted for the remaining factors)

\begin{tabular}{lll}
\hline Factor & $\begin{array}{l}\text { Regression coefficient } \\
(S E M)\end{array}$ & Significance \\
\hline Female sex & $-242(87)$ & \\
Father's height (m) & $+1324(509)$ & $\mathbf{P}<0.01$ \\
Mother's smoking & $-197(85)$ & $\mathbf{P}<0.02$ \\
\hline
\end{tabular}

Table 5 Factors affecting length (\%) in 581 Glasgow infants after adjustment for birthweight. (Each factor adjusted for the remaining factors and length expressed as natural logarithm $\times 100$ )

\begin{tabular}{lll}
\hline Factor & $\begin{array}{l}\text { Regression coefficient } \\
(\text { SEM })\end{array}$ & Significance \\
\hline Female sex & $-2.0(0.2)$ & $\mathrm{P}<0.001$ \\
Mother's height $(\mathrm{m})$ & $+11.1(2.1)$ & $\mathrm{P}<0.001$ \\
Father's height $(\mathrm{m})$ & $+5.9(1.7)$ & $\mathrm{P}<0.001$ \\
Outside lavatory & $+1.6(0.6)$ & $\mathrm{P}<0.01$ \\
No children under 5 & $-0.4(0.2)$ & $\mathrm{P}<0.05$ \\
\hline
\end{tabular}

Table 6 Factors affecting length (\%) in 97 Blackhill and Carntyne infants at 12 months of age, adjusted for length at 1 month. (Each factor adjusted for the remaining factors and length expressed as a percentage of the Glasgow standard)

\begin{tabular}{lll}
\hline Factor & $\begin{array}{l}\text { Regression coefficient } \\
(\text { SEM })\end{array}$ & Significance \\
\hline Father's height $(\mathrm{m})$ & $+9.9(2.5)$ & $\mathrm{P}<0.001$ \\
Father unemployed & $-1.3(0.5)$ & $\mathrm{P}<0.01$ \\
\hline
\end{tabular}

employed $(\mathrm{P}<0.01)$. Adjusting for the difference between Carntyne and Blackhill or alternatively doing a social class adjustment reduced the significance of unemployment $(\mathrm{P}<0.05$ and $\mathrm{P}<0.1$ respectively). Again, no dietary or morbidity factors were relevant.

The difference in length at 12 months between Carntyne and Blackhill babies was $2.6 \%$ unadjusted $(\mathrm{P}<0.001)$; falling to $1.4 \%(\mathrm{P}<0.01)$ adjusted for length at 1 month; $0.8 \%(P<0.1)$ adjusted for father's height as well; and only $0.1 \%(P>0.2)$ adjusted for unemployment, father's height, and length at 1 month.

\section{Discussion}

The cross sectional study shows how early growth in Glasgow babies is related to various genetic and socioeconomic factors. Mother's height is important both for birthweight and for length later in the first year whereas father's height becomes more important subsequently. This accounts for the normal growth pattern seen in infancy ${ }^{9}$ where babies cross centiles from their size at birth, dictated largely by the mother, to size at 12 months, depending on both mother and father. Mother's height became less important during the year, but this trend failed to reach statistical significance. In the longitudinal study by contrast mother's height was not related to birthweight or to length at 12 months, whereas father's height was important for both. Why this should be is not at all clear.

The influence of parental height on infant growth is largely genetically mediated but there may also be 
social factors as suggested by the differences in parental height between the social classes (Table 2). This study identified 4 social factors associated with poor growth, of which unemployment in particular stood out.

The effect of unemployment has shown itself in 2 of the 4 analyses. Firstly babies in the Glasgow cross sectional analysis born of an unemployed father were on average $150 \mathrm{~g}$ lighter than babies whose father was in employment $(P<0.02)$. This was after adjustment for gestational age, sex, parity, mother's height, and social class. The second analysis on babies in Blackhill and Carntyne found that length at 12 months adjusted for length at 1 month and father's height was reduced by $1.3 \%$ when the father was unemployed $(\mathrm{P}<0 \cdot 01)$. In this latter case, where there was a clear difference in length between the 2 groups, adjusting for unemployment explained the difference better than any other factor and reduced it to a non-significant value. In 1 of the other 2 analyses unemployment was also associated with reduced growth but only at the $10 \%$ level of significance.

In a study of 20600 Dublin babies ${ }^{10}$ born in 1978-79 a relation between unemployment and birthweight was also found. The babies were classified according to their father's social class except where he was unemployed, in which case they were put into a separate category. The mean birthweights in social classes 1,2 , and 3 non-manual were all very similar but there was a steady fall in birthweight with social class thereafter. The babies of unemployed fathers had a mean birthweight of $20 \mathrm{~g}$ less than for social class 5 , and $80 \mathrm{~g}$ less than for social class $4(\mathrm{P}<0 \cdot 001)$. Although this difference was not adjusted for gestational age or other relevant factors, it nevertheless showed that babies with unemployed fathers weighed less than babies of the same social class whose fathers were employed.

The National study of health and growth ${ }^{11} 12$ reported an effect of unemployment on attained height among Scottish children aged between 5 and 11 years. Except for the youngest children, however, growth in height over 1 year was unrelated to father's employment status, ${ }^{12}$ suggesting that the deficit in height was the result of poor growth earlier in life.

Other factors emerging from the present study were size of house and outside lavatory (both positive) and number of children under 5 in the family (negative). All are related in an obvious way to poverty or overcrowding and all factors but outside lavatory operate in the expected direction. What is striking though is that diet and morbidity were not found to be important. The association of an outside lavatory with better growth in the cross sectional study is inexplicable, although it may be relevant that in Carntyne there were several outside lavatories and in Blackhill none (Table 2).

It is important to distinguish between association and cause in interpreting the relation between babies growth and unemployment. The link may be causal in that families with an unemployed father have less income leading to a fall in the standard of living and an increase in financial and marital stress. Another possible interpretation is that unemployment does not cause poor growth but rather that unemployment and faltering are present in the same families, both caused by another common factor or factors. Such factors are likely to be related to deprivation, which is usually well summarised by social class. The third rather unlikely possibility is that poor growth in the children leads to unemployment in the fathers. Thus the inferral of causality largely hinges on the question, is the association of poor growth with high unemployment mediated through social class?

Unemployment is closely related to social class in Glasgow as is shown in Table 2. The association of growth with unemployment, however, does not appear to be mediated by social class, since for birthweight at least it is still present after social class $\varnothing$ is adjusted for. Thus there is some evidence to suggest that unemployment among men in Glasgowe may be causally related to growth faltering in their babies. Against this must be set the fact that only 2 of the 4 analyses presented here showed the association.

Another difficulty arises when the effects of nonresponse are considered. The groups of nonresponders in Blackhill and Carntyne were relatively similar to each other in their anthropometry, whereas the responders in the 2 places were very different. Thus the anthropometric middle ground occupied by the defaulters was under represented at 12 months of age, exaggerating the difference between Blackhill and Carntyne. How this may affect the regression coefficients in Table 6 is less easy to predict since data around the mean are by their nature less influential than points near the periphery. If anything the regression slopes will also be slightly exaggerated by the defaulters' absence.

Other studies into the effects of unemployment have concentrated on the unemployed themselves. For example a study of $\mathbf{2 3 0 0}$ men registering as unemployed in the autumn of 1978 concluded that unemployment for periods of up to a year had only a small effect, if any, on health. ${ }^{13}$ (It is unfortunate that in the present study no inquiry was made of the duration of fathers' unemployment as this may have affected the strength of the association). Unemployed men are likely to be less healthy than men in work, 
due to selection effects. ${ }^{1314}$ There is also evidence that wives and families are affected by unemployment. ${ }^{15}$

The most striking work on the health effects of unemployment, however, revealed mortality rather than morbidity.$^{16}$ Brenner used time series analysis to show a strong correlation between the rate of unemployment and total mortality rate several years later. This model has been found to fit data from several countries but for the English data, at least, it exaggerates the true picture. ${ }^{17}$ In addition 2 studies of infant mortality ${ }^{18}{ }^{19}$ found it related to father's unemployment and in the latter study the association remained after adjustment for social class.

If unemployment does cause growth faltering it is important to know whether this matters in practical terms. The size of the unemployment effect was $150 \mathrm{~g}$ or $4.5 \%$ for birthweight and $1.3 \%$ for length at 12 months. For comparison the height deficit of the (rather older) children of unemployed fathers in the National study of health and growth ${ }^{11}$ was 1.5 to $3.5 \mathrm{~cm}$, that is about $2 \%$ on average. Due to its timing in the child's development, the effect on birthweight is probably the more important. The size of the effect is similar to that of smoking in pregnancy, which has been shown to cause a reduction in birthweight of $170 \mathrm{~g}$ (similar to the figure of $200 \mathrm{~g}$ in Table 4) and an associated $28 \%$ increase in perinatal mortality ${ }^{20}$ The excess mortality associated with smoking was greater in social classes 3, 4, and 5 where the mean birthweight was lower than in social classes 1 and 2. Similarly, unemployment may increase perinatal mortality simply by reducing birthweight, particularly as the unemployed are concentrated in social classes 3,4 and 5.

It is clear that in 1975-76 unemployment was associated with impaired growth in Glasgow babies. Whether this association was causal and whether it holds true in other places or at other times is more difficult to answer. The causality argument may be logically unanswerable ${ }^{\mathbf{1 4}}$ but a national study of trends in birthweight over the past 5 years, during which time unemployment rates have increased 3 fold, would provide valuable evidence to test the hypothesis. It is important that such a study be done.

We thank the referee for his comments. The study was funded by the Scottish Home and Health Department.

\section{References}

1 Wedge P, Prosser H. Born to fail? London: Arrow Books in conjunction with the National Children's Bureau, 1973.
${ }^{2}$ Goldstein H. Factors influencing the height of seven year old children - results from the National child development study. Hum Biol 1971;43:92-111.

3 Raby DP. East End district study. Technical working paper. Glasgow: Corporation Planning Department, 1974.

4 Holtermann S. Areas of urban deprivation in Great Britain: an analysis of 1971 Census data. Social Trends No. 6. London: HMSO, 1975:33-47.

5 Boddy FA, Forbes JF. Small area variations in indices of maternal and child health: Glasgow 1975-1977. Paper presented at IXth Scientific Meeting of International Epidemiological Association. Edinburgh: August 1981.

6 Vimpani GV, Vimpani AF, Pocock SJ, Farquhar JW. Differences in physical characteristics, perinatal histories, and social backgrounds between children with growth hormone deficiency and constitutional short stature. Arch Dis Child 1981 ;56:922-8.

7 Donnet ML, Cole TJ, Scott TM, Stanfield JP. Diet, growth and health of infants in a disadvantaged inner city environment in Glasgow. In: Turner MR, ed. Nutrition and health, $a$ perspective. Proceedings, British Nutrition Foundation, 3rd Annual Conference. London: MTP Press, 1982.

8 Cole TJ, Donnet ML, Stanfield JP. Weight-for-height indices to assess nutritional status-a new index on a slide-rule. Am J Clin Nutr 1981 ;34:1935-43.

9 Tanner JM. Catch-up growth in man. Br Med Bull $1981 ; 37: 233-8$.

10 Dowding VM. New assessment of the effects of birth order and socioeconomic status on birth weight. $\mathrm{Br} \mathrm{Med} \mathrm{J}$ 1981 ; i:683-6.

11 Rona RJ, Swan AV, Altman DG. Social factors and height of primary schoolchildren in England and Scotland. $J$ Epidemiol Community Health 1978;32:147-54.

12 Smith AM, Chinn S, Rona RJ, Social factors and height gain of primary schoolchildren in England and Scotland. Ann Hum Biol 1980;7:115-24.

13 Ramsden S, Smee C. The health of unemployed men: DHSS cohort study. Employment Gazette 1981: 397-401.

14 Cook DG, Cummins RO, Bartley MJ, Shaper AG. Health of unemployed middle-aged men in Great Britain. Lancet 1982; : 1290-4.

15 Fagin L. Unemployment and health in families. London: DHSS, 1981.

16 Brenner MH. Mortality and the national economy. A review, and the experience of England and Wales, 1936-76. Lancet 1979 ;ii :568-73.

17 Gravelle HSE, Hutchinson G, Stern J. Mortality and unemployment: a critique of Brenner's time-series analysis. Lancet 1981 ;ii:675-9.

18 Woolf B. Studies in infant mortality. Part II: social aetiology of stillbirths and infant deaths in county boroughs of England and Wales. British Journal of Social Medicine 1947;1:73-125.

19 Brennan ME, Lancashire R. Association of childhood mortality with housing and unemployment. $J$ Epidemiol Community Health 1978;32:28-33.

20 Butler NR, Goldstein H, Ross EM. Cigarette smoking in pregnancy: its influence on birth weight and perinatal mortality. Br Med J 1972; ii :127-30.

Correspondence to $\mathbf{T} \mathbf{J}$ Cole, Dunn Nutrition Unit, Milton Road, Cambridge CB4 1 XJ.

Received 22 March 1983 